\title{
Hysteroscopy- as a Diagnostic and Therapeutic Measure in Infertility- A Review on it Janna $\mathrm{JR}^{1}$
}

\begin{abstract}
Background: Although hysteroscopy has proved to be a standard diagnostic tool in the uterine pathology, its use in the primary infertility workup is not established yet and as a therapeutic role in the management of infertility although proved, not widespread in use. I therefore aimed to review the journals to work out on diagnostic and therapeutic role of hysteroscopy in the management of infertility. Method: The literature searched was published in the English language using terms for 'hysteroscopy, infertility, diagnostic, therapeutic, pregnancy or conception rate, polyps, fibroids, congenital anomalies, Asherman's syndrome, adhesions and assisted reproductive techniques in MEDLINE, EMBASE, GOOGLE, SAGES, RCOG for relevant studies. Importance given to randomized controlled trial, prospective or retrospective studies with large study population. Results: I summarized and appraised the evidence for the benefit yielded by the use of hysteroscopy. It is found that as diagnostic tool in infertility workup hysteroscopy is superior to other available methods. Although there was no significant difference regarding findings of intrauterine pathology between primary and secondary infertility, it is obvious that hysteroscopic removal of these pathology increased pregnancy rate not only in these two groups but also in In-vitro fertilization (IVF) and Intrauterine insemination (IUI) failure cases. Conclusion: Consideration should be given not only as a therapeutic role of hysteroscopy but also as a primary infertility workup in the management of infertility.
\end{abstract}

\section{Keywords}

Hysteroscopy, infertility, diagnostic, therapeutic, pregnancy rate.

\section{Introduction}

Traditionally, hysteroscopy is being used for diagnostic and operative intervention for endometrial polyps, submucous and pedunculated myomas, intrauterine adhesions, and uterine septa. It is also useful for the diagnosis of congenital anomalies and evaluating endocervical anatomy.

It is widely accepted that a complete infertility workup should include an evaluation of the uterine cavity. Uterine abnormalities, congenital or acquired, are implicated as one of the causes of infertility. In fact, infertility related to uterine cavity abnormalities has been estimated to be the causal factor in as many as $10 \%$ to $15 \%$ of couples seeking treatment. Moreover, abnormal uterine findings have been found in $34 \%$ to $62 \%$ of infertile women. ${ }^{4}$

Today, hysteroscopy is considered the gold standard for evaluating the uterine cavity, and due to improved endoscopic developments, can be performed reliably and safely as an office procedure. ${ }^{5,6}$ Direct view of the uterine cavity offers a significant advantage over other blind or indirect diagnostic methods. ${ }^{7}$

Later studies have shown a correlation of only $65 \%$ between findings diagnosed with hysterosalpingogram (HSG) compared with those diagnosed with hysteroscopy. ${ }^{8}$ The role of hysteroscopy in infertility is to detect possible intrauter- 
intrauterine changes that could interfere with implantation or growth, or both, of the conceptus, and to evaluate the benefit of different treatment modalities in restoring a normal endometrial environment. ${ }^{9}$

Hysteroscopy can diagnose small intrauterine lesions that might affect fertility; much more precisely compared to HSG and transvaginal sonogram (TVS) ${ }^{27}$ In view of all of the above, it is clear why many authors believe that uterine and endometrial integrity should be evaluated primarily by hysteroscopy in the infertile/ In vitro fertilization - Embryo Transfer (IVF-ET) treated population. ${ }^{11-15}$

With the invention of miniature hysteroscope, it is possible to perform hysteroscopy in an office set-up, with or without local or general anesthesia for diagnostic and certain therapeutic intervention. ${ }^{16}$

This present review aims to examine the effectiveness of the Hysteroscopy as a diagnostic tool in infertility workup and in removal of endometrial polyps, sub-mucous fibroids, septate uterus or intrauterine adhesions in subfertile women.

It also aimed to review the effectiveness of diagnostic or operative hysteroscopy in women treated by IVF/IUI.

The main outcome measure was conception/ pregnancy rate.

\section{Methods}

The literature searched was published in the English language using terms for hysteroscopy, infertility, diagnostic, therapeutic, pregnancy or conception rate, polyps, fibroids, congenital anomalies, Asherman's syndrome, adhesions and assisted reproductive techniques in MED-
LINE, EMBASE, GOOGLE, SAGES, RCOG for relevant studies. Importance given to randomized controlled trial, prospective or retrospective studies with large study population. The first group included studies on hysteroscopy as diagnostic tool in infertility workup.

The second group involved studies on Hysteroscopy as a therapeutic measure in intrauterine pathology of infertile patient and pregnancy outcome.

The third group included studies on diagnostic or operative hysteroscopy and pregnancy rates in subfertile patients treated by IVF or IUI.

\section{Results}

To find out the outcome of present study, results of different studies are summarized as below:

\section{Hysteroscopy as a diagnostic tool in infertil-} ity workup:

Monty Pansky et al ${ }^{19}$ reported a retrospective analysis where hysteroscopy was performed in 221 infertile women. Among women with primary infertility, intrauterine pathologies were diagnosed in $28(26 \%)$ and with secondary infertility, intrauterine pathologies were diagnosed in 36 women $(31 \%)$.

Horvitz et al ${ }^{19}$ evaluated the effectiveness in 93 infertile patients with normal uterine cavity in HSG who underwent both diagnostic laparoscopy \& hysteroscopy-showed normal cavity in 80 cases-giving FNR of $12 \%$ for HSG.

In Sahu L et $\mathrm{al}^{21}$, an analysis was reported which was carried prospectively with 324 infertile patients using a flexible hysteroscope. Hysteroscopy was normal in $65.12 \%$ of patients, cervicoisthmic abnormalities were present in $6.48 \%$ of patients with cervical stenosis being the major 
$6.48 \%$ of patients with cervical stenosis being the major abnormality. Observed abnormalities were septate uterus in 10 cases, intrauterine synechiae in 16 cases, sub mucus myoma in 2 cases, deformed cavity in 10 cases and endometrial polyp in 2 cases. Ostial fibrosis was observed in 29 patients. Endometrial abnormalities (fibrosis, inflammation) were observed in 30 patients. Seven patients turned out to have genital tuberculosis with endometrial biopsy. No significance was found regarding the total number of intrauterine pathologies when comparing the groups of primary versus secondary infertility.

Abrahim et $\mathrm{al}^{22}$, compared HSC and HSG as diagnostic tool in 464 infertile women. Compared to HSC the sensitivity of HSG was $98 \%$, but its specificity only $15 \%$, the positive predictive value $45 \%$, and negative predictive value $95 \%$. On hysteroscopy normal uterine cavity was found in $53 \%$ of the cases with a filling defect and in $56 \%$ of those with uterine wall irregularity on HSG.

\section{Hysteroscopy as a therapeutic measure in intrauterine pathology of infertile patient and pregnancy outcome:}

Marviel et $\mathrm{al}^{23}$ examined the role of hysteroscopy in diagnosis and treatment. As assessed by the percentage of patients with each indication who subsequently became pregnant, the results of surgical hysteroscopy have been satisfactory: 62 per cent (\%) of cases after myomectomy, $66 \%$ after section of uterine septa, and $61 \%$ after treatment of complicated adhesions.

Bosteels $\mathrm{J}$ et $\mathrm{al}^{24}$ assessed the effects of the hysteroscopic removal of endometrial polyps, submucous fibroids, uterine septum or intrauter- ine adhesions in women with otherwise unexplained subfertility or prior to intrauterine insemination (IUI), in vitro fertilization (IVF) or intracytoplasmic sperm injection (ICSI). Although no significant difference found regarding pregnancy rate after myomectomy, hysteroscopic removal of polyps prior to IUI increases the odds of clinical pregnancy compared to diagnostic hysteroscopy and polyp biopsy only ( $\mathrm{P}<$ $0.00001,204$ women, high-quality evidence).

Rocai $\mathrm{P}$ et $\mathrm{al}^{25}$ evaluated the reproductive outcome of hysteroscopic metroplasty performed in women with septate uterus and otherwise unexplained primary infertility in prospective observational study. Of 61 women, (41\%) conceived within 8-14 (mean 11.2) months after hysteroscopic metroplasty.

Makaru $\mathrm{K}$ et $\mathrm{al}^{26}$ investigated the fertility outcomes of infertile patients having proximal tubal obstruction treated with hysteroscopic tubal catheterization (HCT) for recanalization under diagnostic laparoscopy. In the 35 patients with confirmed tubal obstruction, HCT was performed in 54 fallopian tubes. The success rate of recanalization was $25.9 \%(14 / 54)$ per tube and $37.1 \%(13 / 35)$ per patient.

3. Role of diagnostic and therapeutic hysteroscopy in infertility patient treated with IVFIUI:

Flavio G Oliveria et $\mathrm{al}^{27}$ assessed hysteroscopic findings in patients undergoing IVF-ET who repeatedly failed to conceive despite transfer of good-quality embryo in a prospective observational study. Total fifty-five patients with a normal uterine cavity on hysterosalpingography before the initial IVF-ET 
cycle and two previous failed IVF-ET attempts despite transfer of a minimum of two goodquality embryos on each occasion.

Twenty-five patients (45\%) had abnormal endometrial findings and underwent treatment to correct the lesions. All patients underwent a third IVF-ET cycle. Pregnancy (50\% vs. $20 \%$ ) and implantation ( $19 \%$ vs. $5.5 \%)$ rates were significantly higher in patients who were treated for uterine abnormalities than in patients who had normal uterine cavities on hysteroscopy.

Tirso Perez $\mathrm{M}$ et $\mathrm{al}^{28}$ examined a total of 215 infertile women with ultrasonographically diagnosed endometrial polyps undergoing IUI were randomly allocated to one of two pretreatment groups. Hysteroscopic polypectomy was performed in the study group. Diagnostic hysteroscopy and polyp biopsy was performed in the control group. A total of 93 pregnancies occurred, 64 in the study group and 29 in the control group. Women in the study group had a better possibility of becoming pregnant after polypectomy, with a relative risk of 2.1 (95\% confidence interval 1.5-2.9). Pregnancies in the study group were obtained before the first IUI in $65 \%$ of cases.

Rama Raju et $\mathrm{al}^{29}$ aimed to evaluate if the diagnosis and treatemet of uterine cavity abnormalities by hysteroscopy in patients undergoing IVF programme is of any value in improving clinical pregnancy outcome. Methods: 520 patients participated in this prospective randomized study and were classified into two groups. Group I ( $n=265)$ without office hysteroscopy. Group II $(n=255)$ had office hysteroscopy and was sub classified into Group II a. and Group II b. Group II a $(n=160)$ had normal hysteroscopic findings whereas Group $\Pi$ b $(n=95)$ had abnormal office hysteroscopy findings, which were corrected at the same time. Result: There was no difference in the mean number of oocytes retrieved, fertilization rate, and number of embryos transferred among the patients in different groups. Statistically significant difference was observed in terms of clinical pregnancy rates between Group I and Group II a (26.2 and 44.44\%, P < 0.05), and Group I and Group II b (26.2 and 39.55\%, P < 0.05 ), respectively.

In Mary D et al study ${ }^{15}$, one thousand consecutive infertile patients scheduled for in vitro fertilization underwent office hysteroscopy.

Sixty-two percent of patients had a normal uterine cavity. Thirty-two percent had endometrial polyps. Other pathology included submucous fibroids $(3 \%)$, intrauterine adhesions $(3 \%)$, polypoid endometrium $(0.9 \%)$, septum $(0.5 \%)$ retained products of conception $(0.3 \%)$, and bicornuate uterus $(0.3 \%)$. The pathology was treated in all patients without complication

\section{Discussion}

While debating the need for routine diagnostic hysteroscopy in the evaluation of the infertile woman, one must keep in mind that this procedure today is no longer a complicated but rather a simple, fast, outpatient procedure, requiring short training with high success rates.

Diagnostic hysteroscopy allows complete, accurate identification of intrauterine abnormalities that might negatively affect endometrial receptivity and implantation. The information derived from hysteroscopy helps the physician to institute appropriate therapy, and by doing so improve conception rates over shorter intervals. 
Monty Pansky et al ${ }^{19}$ shows that the incidence of uterine pathologies (congenital and acquired) in women with primary or secondary infertility approximates $30 \%$, thus justifying, in their opinion, the use of diagnostic hysteroscopy in the primary routine investigation of infertile women \& because no significant difference was found regarding the intrauterine findings between women with primary and secondary infertility, they believe that diagnostic hysteroscopy has a similar importance in the evaluation of patients with both primary and secondary infertility.

On the other hand, Horvitz et $\mathrm{al}^{20}$ found that in the absence of a positive history or a radiographical suggestion of endometrial abnormalities, or both, HSC made little diagnostic contribution towards elucidating the cause of female infertility or to finding a pathology that could affect the chances of achieving a normal pregnancy. However, Sahu et $\mathrm{al}^{21}$ supports the findings of Monty Pansky. Sahu found that rates of abnormal findings in infertile patient who underwent diagnostic hysteroscopy was $34.88 \%$ cases. This data is an additional argument to suggest hysteroscopy as part of investigation in infertile woman. Routine diagnostic hysteroscopy should be part of an infertility workup in primary and secondary infertility.

In addition, Abrahim et al ${ }^{22}$ compared hysteroscopy with HSG as a diagnostic tool and concluded that Hysteroscopy, allows a safe and rapid direct visualization of the uterine cavity, in view of low positive predictive value and the low specificity of the HSG, they believe it is superior to HSG in the identification of intrauterine pathology. In view of the low positive predictive value it could be replaced by the diagnostic hysteroscopy as a first line infertility investigation. Approximately $15 \%$ of couples are affected with subfertility, of which up to $20 \%$ remain unexplained. Uterine cavity abnormalities can be a contributing cause of subfertility and recurrent implantation failure. Uterine cavity assessment has been suggested as a routine investigation in the evaluation of subfertile women. Identifying intrauterine abnormalities, hysteroscopy is considered as the definitive diagnostic tool to evaluate any abnormality suspected on hysterosalpingography, transvaginal ultrasound scan or saline hysterosonography during routine investigation of infertile patients.

Minimally invasive hysteroscope have minimized the pain experienced by patients during the procedure and made it feasible to use hysteroscopy as a routine outpatient examination.

While the relationship between congenital uterine malformations and impaired pregnancy outcome (such as recurrent pregnancy loss, late abortions, preterm deliveries, etc.) is quite established, the issue of these malformations as a cause of infertility is still debatable. The incidence of uterine malformations in other series of infertile patients varies between $1 \%$ and $26 \%$, with a mean incidence of $3.4 \%{ }^{31}$

Regarding hysteroscopic myomectomy Bosteel J et $\mathrm{al}^{24}$ found that hysteroscopic myomectomy might increase the odds of clinical pregnancy in women with unexplained subfertility and submucous fibroids, but the evidence is at present not conclusive. 
The hysteroscopic removal of endometrial polyps suspected on ultrasound in women prior to IUI might increase the clinical pregnancy rate. More randomized studies are needed to substantiate the effectiveness of the hysteroscopic removal of suspected endometrial polyps, submucous fibroids, uterine septum or intrauterine adhesions in women with unexplained subfertility or prior to IUI, IVF or ICSI.

Rocai $P$ et $\mathrm{al}^{25}$ evaluated the reproductive outcome of hysteroscopic metroplasty performed in women with septate uterus and otherwise unexplained primary infertility in prospective observational study and concluded that women with uterine septum and otherwise unexplained infertility might benefit from hysteroscopic metroplasty.

Makaru $\mathrm{K}$ et $\mathrm{al}^{26}$ investigate the fertility outcomes of infertile patients having proximal tubal obstruction treated with hysteroscopic tubal catheterization (HCT) for recanalization under diagnostic laparoscopy came in conclusion that HCT under laparoscopy is an option for couples with tubal infertility who do not prefer IVF-ET. Flavio G Oliveria et $\mathrm{al}^{27}$ assessed hysteroscopic findings in patients undergoing IVF-ET who repeatedly failed to conceive despite transfer of good-quality embryo in a prospective observational study came into conclusion that the incidence of pathologic findings on hysteroscopy is high in patients with repeated failures of IVF-ET. Evaluation of endometrial integrity by hysteroscopy is highly valuable and should be applied to all such cases.

Tirso Perez $\mathrm{M}$ et $\mathrm{al}^{28}$ also supported it after examining a total of 221 infertile women ultrasonologically diagnosed endometrial polyp who underwent hysteroscopic polypectomy. Findings of the study suggest that hysteroscopic polypectomy before IUI is an effective measure.

Furthermore, Rama Raju et $\mathrm{al}^{29}$ stressed that patients with recurrent IVF embryo transfer failures after normal hysterosalpingography findings should also be reevaluated using hysteroscopy prior to further commencing IVFembryo transfer cycles in order to enhance the clinical pregnancy rates.

\section{Conclusion}

Hysteroscopy has, for decades, played an important role in the diagnosis and treatment of infertile patients, and will continue to do so. Newer technology has, in some ways, decreased the necessity for hysteroscopy for diagnosis, but also increased its utility for treatment.

This review literature has found that different good quality study supporting the view that hysteroscopy should be included in the infertility workup in view of its diagnostic accuracy over other methods. Not only in its diagnostic accuracy but also its important role in the management of infertile patients and increased pregnancy rate has supported by most of the study. So it can be recommending that hysteroscopy should be included not only in the management of infertility patient but also in the primary infertility workup.

\section{References}

1. Glatstein, IZ, Harlow, BL and Hornstein, MD. Practice patterns among reproductive endocrinologists: the infertility evaluation. Fertil. Steril. 1997; 67(3): 443-51

2. Tailor PJ, Correlations in infertility: symptomatology, hysterosalpingography and hysteroscopy. J Reprod Med, 1977 Jun; 18(6):339-42

3. Lasmar RB, Barrozo PR, Parente RC, et al. Hysteroscopic evaluation in patients with infertility. Rev Bras Ginecol 
Obstet, 2010 Aug; 32(8):393-7.

4. Brown SE, Coddington CC, Schnorr J, Toner JP, Gibbons W, Oehninger S. Evaluation of outpatient hysteroscopy, saline infusion hysterosonography and hysterosalpingography in infertile women: a prospective, randomized study. Fertil Steril. 2000; 74(5):1029-34.

5. Shushan A, Rojansky N. Should hysteroscopy be a part of thebasic infertility workup? Hum Reprod. 1999; 14(8): 1923-24.

6. Gordts S, Campo R, Puttemans $\mathrm{P}$, et al. Investigation of the infertile couple. Hum Reprod. 2002; 17(7): 1684-7.

7. Prevedourakis C, Loutradis D, Kalianidis C, Makris N, Aravantinos D. Hysterosalpingography and hysteroscopy in female infertility. Hum Reprod. 1994; 9(12): 2353-5

8. Wang CW, Lee CL, Lai YM, Tsai CC, Chang MY, Soong YK. Comparison of hysterosalpingography and hysteroscopy in female infertility. J Am Assoc Gynecol Laparosc, 1996; 3(4): 581-4.

9. Campo R, Van Belle Y, Rombauts L, Brosens I, Gordts S. Office mini-hysteroscopy. Hum

Reprod Update, 1999; 5(1): 73-81.

10. Oliveira FG, Abdelmassih VG, Diamond MP, Dozortsev

D, Nagy ZP, Abdelmassih R. Uterine cavity findings and hysteroscopic interventions in patients undergoing in vitro fertilization-embryo transfer who repeatedly cannot conceive. Fertil Steril. 2003; 80(6): 1371-5.

11. La Sala GB, Montanari R, Dessanti L, Cigarini C, Sartori

F. The role of diagnostic hysteroscopy and endometrial biopsy in assisted reproductive technologies. Fertil Steril. 1998; 70: 378-80.

12. Kessler I, Lancet M. Hysterography and hysteroscopy: a comparison. Fertil Steril. 1986; 46(4): 709-10.

13. Nawroth F, Foth D. Mini hysteroscopy as routine diagnostic procedure in women with primary infertility. J Am Assoc Gynecol Laparosc. 2003; 10(3): 396-8.

14. Brusco GF, Arena S, Angelini A. The role of diagnostic hysteroscopy in infertile women. Minerva Ginecol. 2001; 53(5): 313-9.

15. Mary D, Hinckley MD, Milki AA. 1000 office-based hysteroscopies prior to in vitro fertilization: feasibility and findings. JSLS. 2004; 8(2): 103-7.

16. Bettochi S, Cecio Nappi L, Di venere R, Ransini MR, Peiiegrino A, Marello F. Operative office hysteroscopy with or without anaesthesia. A study of 4863 cases performed with mechanical instruments. J Am Assoc Gynecol Laparosc, 2004; 11: 59-61.
17.Rimbach S, Wallwiener D, Barth C, Heberling D, Bastert G. Comparison of in-vitro falloposcopy with tubal histology in the diagnosis of Fallopian tube pathology. Hum. Reprod, 1996; 11(10): 2130-3. Hum. Reprod, 1996; 11(10): 2130-3. 18.Dechaud H., Daures JP and Hedon B. Prospective evaluation of Falloposcopy. Hum. Reprod., 1998; 13(7): 1815-8.

19. Pansky M, Fiengold M, Sagi $R$, Halperin A, Schneider D, and Halperin R. Diagnostic hysteroscopy as a primary tool in basic infertility workup. JSLS, 2006 Apr-Jun; 10(2): 231-3

20. Hourvitz A, Ledee N, Gervaise A, Fernandez H, Frydman $\mathrm{R}$, Olivennes F. Should diagnostic hysteroscopy be a routine procedure during diagnostic laparoscopy in women with normal hysterosalpingography? Reprod Biomed Online, 2000 May-Jun; 4(3): 256-60

21. Sahu L, Tempe A, Gupta S. Hysteroscopic evaluation in infertile patients: a prospective study. Int J Reprod Contracept Obstet Gynecol, 2012 Dec; 1(1): 37-41.

22. Golan A, Eilat E, Ron-el R, Herman A, Soffer Y, Bukovsky I. Hysteroscopy is superior to hysterosalpingography in infertility investigation. Acta Obstetricia et Gynecologica Scandinavica, 1996 July; 75(7): 654-6.

23. Merviel P, Mergui JL, Sananes S, Antoin Jm, Salat-Baroux J, Uzan S. Role of hysteroscopy in the diagnosis and treatment of infertility. Press Med, 2000 Jul 1; 29(23):1302-10.

24. Bosteels J, Kasius J, Weyers S, Broekmans FJ, Mol BW, D'Hooghe TM. Hysteroscopy for treating subfertility associated with suspected major uterine cavity abnormalities. Cochrane Database Syst Rev, 2013 Jan 31; (1).

25.Pabuccu R, Gomel V. Reproductive outcome after hysteroscopic metroplasty in women with septate uterus and otherwise unexplained infertility. 2004 June; 81(6): 1675-8.

26. Mekaru K, Yagi C, Asato K, Masamoto H, Sakumoto K, Aoki Y. Hysteroscopic tubal catheterization under laparoscopy for proximal tubal obstruction. Arch Gynaecol Obstet, 2011 Dec; 284(6): 1573-6.

26. Mekaru K, Yagi C, Asato K, Masamoto H, Sakumoto K, Aoki Y. Hysteroscopic tubal catheterization under laparoscopy for proximal tubal obstruction. Arch Gynaecol Obstet, 2011 Dec; 284(6): 1573-6.

27. Oliveria FG, Abdelmassih VG, Diamond MP, Dozortsev D, Nagy ZP, Abdelmassih R. Uterine cavity findings and hysteroscopic interventions in patients undergoing in vitro fertilization-embryo transfer who repeatedly cannot conceive. Fertility and Sterlity. 2003 Dec; 80(6): 1371-5. 
28. Perez-Medina T, Bajo-Arenas J, Salazar F, et al. Endometrial polyps and their implication in the pregnancy rates of patients undergoing intrauterine insemination: a prospective, randomized study. Human reproduction, 2005; 20(6): 1632-5. 29. Rama Raju GA, Shashi Kumari G, Krishna KM, Prakash GJ, Madan K. Assessment of uterine cavity by hysteroscopy in assisted reproduction programme and its influence on pregnancy outcome. Archives of Gynaecology and Obstetrics, 2006 June; 274(3): 160-4.

30.Diagnostic evaluation of the infertile female: a committee opinion. Practice Committee of American Society for Reproductive Medicine. Fertil Steril, 2012 Aug; 98(2):302-7. 